\title{
Introducing Web 2.0: RSS trends for health librarians
}

\author{
Eugene Barsky
}

In Jenny Levine's excellent blog The Shifted Librarian (http:// www.theshiftedlibrarian.com/), I recently noticed an interesting debate about Web 2.0 that I had completely missed.

Knowing very little about Web 2.0 or its implications for my work as a health sciences information professional, I chose to read Tim O'Reilly's article "What Is Web 2.0: design patterns and business models for the next generation of software" (http://www.oreillynet.com/lpt/a/6228). O'Reilly comes up with this somewhat technical definition:

Web 2.0 is the network as platform, spanning all connected devices; Web 2.0 applications are those that make the most of the intrinsic advantages of that platform: delivering software as a continually-updated service that gets better the more people use it, consuming and remixing data from multiple sources, including individual users, while providing their own data and services in a form that allows remixing by others, creating network effects through an "architecture of participation," and going beyond the page metaphor of Web 1.0 to deliver rich user experiences.

In other words, Web 2.0 has enormous potential to bring user-generated content to the Internet. The idea is to free data from corporative control and allow anyone to assemble and locate content to meet their own needs or the needs of clients. Rather than having to conform to the paths laid out for us by content owners or their intermediaries, we create the content.

Is Web 2.0 something that we need to start thinking about? What does it mean for how we provide medical information services? Perhaps this is another bubble that will disappear if we just ignore it for a while. However, in thinking about this, I would like to share with you some ideas and tools that will set up the way for Web 2.0. I have written a series of short reviews of the major trends and surmised their application in health and medical information services.

Let's start with RSS feeds. In subsequent articles we'll move onto blogging and podcasting, continue with Wikis and folksonomies (tagging), and conclude with social networking tools.

\section{RSS}

RSS (RDF Site Summary, or Rich Site Summary, or Really Simple Syndication) is an easy-to-use XML format for distrib-

E. Barsky. Irving K. Barber Learning Centre, University of British Columbia, 1961 East Mall, Vancouver, BC V6T 1Z1, Canada (e-mail: eugene.barsky@ubc.ca). uting content on the Web. It has been around since the late 1990s but has received considerable attention very recently because of the expansion of blogging. In short, RSS is a simple XML syntax for describing recent additions of content to a Web site. These additions can include news items, blog updates, library acquisitions, or any other information elements. A Web site with one or more RSS feeds is said to be syndicated. Users subscribe to the feeds using an RSS aggregator or newsreader that crawls the sites on a regular basis, usually several times per hour. An aggregator displays feeds and enables users to organize them and to access related Web pages when these are available. RSS feeds can have the following applications for health librarians:

(1) Blog updates - Today many librarians act as communicators while writing and maintaining blogs. RSS feeds mean that blog readers can be informed immediately when a blog is updated. Most blog software includes embedded RSS feed generation. For instance, you can follow an excellent Dean Giustini's UBC Google Scholar blog by subscribing to its RSS feed (http://weblogs. elearning.ubc.ca/googlescholar/index.xml).

(2) Newspaper and journal articles - Increasingly, many newspapers and scientific journals provide new content via RSS feeds. My daily favourites are the following: The New York Times Health section feed (http://www. nytimes.com/services/xml/rss/nyt/Health.xml), International Herald Tribune Health and Science RSS (http://www.iht. com/rss/healthscience.xml), and CBC Health and Science News (http://rss.cbc.ca/healthsciencenews.xml).

(3) Press releases and announcements - RSS can be very useful for more formal announcements. For instance, the US Food and Drug Administration (FDA) provides seven RSS feeds, including the agency's press releases, recent recalls, withdrawals, and institutional alerts (http://www. fda.gov/cdrh/rss.html).

(4) News and database updates - Some major services, such as Google News (http://news.google.ca/intl/en_ca/news_ feed_terms.html) and PubMed (http://www.nlm.nih.gov/ pubs/techbull/mj05/mj05_rss.html), have recently started to provide search results in RSS format. RSS is likely to become increasingly common for users to stay current in the future, particularly with respect to keeping up with new research.

\section{RSS readers/aggregators}

There are a number of RSS aggregators available. The aggregators can be categorized as follows: 
(1) Web-based readers - These Web sites collect RSS feeds online and can be accessed from any Internet-enabled computer. Bloglines (http://www.bloglines.com/) is my favorite free online RSS reader, allowing easy access to selected RSS feeds from both my home and work desktops.

(2) Standalone clients - These software packages access selected RSS feeds and download results to your computer. SharpReader (www.sharpreader.net) is my favorite free standalone RSS reader.

(3) Plugins - These programs are integrated into software packages installed on your desktop (e.g., Microsoft Outlook).

For an easy introduction to RSS feeds, I recommend a simple Web-based aggregator such as Bloglines. Since Bloglines is Web-based, there is no software to download, and subscribed feeds can be accessed from any Internetconnected machine.

\section{Writing RSS}

Making an RSS file is easy to do. If you understand basic HTML, you know enough to use someone else's RSS to make your own file. Don't know HTML? You might consider starting a blog, as the majority of today's blogging tools automatically generate RSS files. Danny Sullivan's SearchEngineWatch offers great advice for compiling a simple RSS feed (http://searchenginewatch.com/sereport/article.php/2175271). In addition, Syndic8's How To section also lists numerous tutorials that describe the building of RSS files (http://www. syndic8.com/documents.php?Section=HowTo).

\section{Conclusion}

In summary, my sense is that 2006 will be a year of increasingly pushed and user-created content on the Internet. RSS will not necessarily become the core of Web 2.0 services, as it does not include any transactional pulled component. In other words, you cannot use RSS to purchase a DVD or reserve an airline flight. However, for information professionals, particularly those in life and health sciences, and those that use the Web primarily to retrieve, provide, and update information, RSS will be increasingly more prominent. RSS is becoming an essential communication tool that allows us to provide the most up-to-date information to our clients. It is definitely a trend to watch. 
This article has been cited by:

1. Eugene Barsky, Allan Cho. 2007. Introducing Web 2.0: social search for health librarians. Journal of the Canadian Health Libraries Association 28:2, 59-61. [Abstract] [PDF] [PDF Plus]

2. Allan Cho. 2007. An introduction to mashups for health librarians. Journal of the Canadian Health Libraries Association 28:1, 19-22. [Citation] [PDF] [PDF Plus]

3. Eugene Barsky, Michelle Purdon. 2006. Introducing Web 2.0: social networking and social bookmarking for health librarians. Journal of the Canadian Health Libraries Association 27:3, 65-67. [Citation] [PDF] [PDF Plus]

4. Eugene Barsky. 2006. Introducing Web 2.0: weblogs and podcasting for health librarians. Journal of the Canadian Health Libraries Association 27:2, 33-34. [Citation] [PDF] [PDF Plus] 